\title{
Guaranteed predictive estimation of solutions of system of differential equations with the Gompertzian dynamics
}

\author{
Nakonechnyi O., Zinko P., Shevchuk I. \\ Taras Shevchenko National University of Kyiv, 64/13 Volodymyrska Str., 01601, Kyiv, Ukraine
}

(Received 20 March 2019; Accepted 2 May 2019)

\begin{abstract}
In this paper, we have introduced a mathematical model to describe processes that grow in time rapidly. The model has the form of a system of non-linear differential equations with Gompertzian dynamics and non-stationary parameters. We have formulated and studied the problem of finding the predictive estimation for the systems of differential equations with Gompertzian dynamics, for the case of continuous observation. We have suggested the algorithms for building guaranteed predictive estimations for the model. We have presented as an example, the results of numerical experiments to build guaranteed estimates for the mathematical model of spreading some type of information in society. The suggested approach presents both theoretical interest and important practical meaning.

Keywords: system of differential non-linear equations, Gompertzian dynamics, guaranteed predictive estimation, uncertainty.
\end{abstract}

2000 MSC: $34-02,90-02$

UDC: $517.9,519.87$

DOI: $10.23939 / \mathrm{mmc} 2019.01 .092$

\section{Introduction}

Gompertz curves adequately present processes of growth of tumors, processes of disease spread, processes within a population and others. In the works [1,2], the mathematical models in the form of systems of differential equations with Gompertzian dynamics are suggested.

Nakonechnyi O. G. formulated the problem statement of finding guaranteed and optimal estimations in his works [3-7]. For example, [5] suggested the construction of algorithms of averaged optimal root mean squared predictive estimation and guaranteed predictive estimation. Nakonechnyi O. G. and coauthors in their work [6] developed the algorithms of constructing optimal functional estimations and guaranteed estimations of non-stationary parameters of differential equations. In the work [7] the algorithms of building optimal estimations and guaranteed estimations of non-stationary parameters of difference non-linear equations were suggested.

The statement of the problem of finding the guaranteed estimation for systems of differential equations with Gompertzian dynamics was given in [8].

\section{Assumptions and notations}

Now let us take a detailed look at the non-linear continuous system of differential equations with the initial conditions:

$$
\begin{aligned}
\frac{d x_{k}(t ; f(\cdot))}{d t} & =\left[\left(B(t) f(t), e^{k}\right)+\sum_{j=1}^{n}\left(A(t) e^{k}, e^{j}\right) \ln x_{k}(t ; f(\cdot))\right] x_{k}(t ; f(\cdot)), \quad t \in\left(0, T_{2}\right), \\
x_{k}(0 ; f(\cdot)) & =x_{k}^{0}>0, \quad k=\overline{1, n},
\end{aligned}
$$

where the matrix-valued functions $A(t) \in \mathbb{R}^{n \times n}, B(t) \in \mathbb{R}^{n \times m}, t \in\left(0, T_{2}\right)$ has continuous components; $f(\cdot) \in \mathbb{R}^{m}, f(\cdot) \in \mathbb{L}_{2}\left(0, T_{2}\right)$ is the unknown vector-valued function; vector $e^{k}$ is the $k$-th unit vector, $k=\overline{1, n}$. And the solutions of (1) satisfies the inequalities $x_{k}(t ; f(\cdot))>0, t \in\left(0, T_{2}\right), k=\overline{1, n}$. 
Suppose that $y_{i}(t), t \in\left(0, T_{1}\right), T_{1} \leqslant T_{2}, i=\overline{1, n_{0}}, n_{0} \leqslant n$ are the known observations of the vector-valued functions $x_{i}(t ; f(\cdot)), t \in\left(0, T_{1}\right)$ with the certain $f(t), t \in\left(0, T_{1}\right)$ :

$$
y_{i}(t)=x_{i}(t ; f(\cdot))+v_{i}(t), \quad t \in\left(0, T_{1}\right), \quad i=\overline{1, n_{0}},
$$

where $v_{i}(t), t \in\left(0, T_{1}\right), i=\overline{1, n_{0}}$ are the observed errors.

Let us denote $x(t ; f(\cdot))=\left(x_{1}(t ; f(\cdot)), \ldots, x_{n}(t ; f(\cdot))\right)^{\mathrm{T}}, t \in\left(0, T_{2}\right) ; v(t)=\left(v_{1}(t), \ldots, v_{n_{0}}(t)\right)^{\mathrm{T}}$, $t \in\left(0, T_{1}\right)$, where $\mathrm{T}$ is the designation of transpose.

Assume that $f(\cdot) \in G$, where $G$ is bounded, convex and closed set in $\mathbb{L}_{2}\left(0, T_{2}\right) ; v_{i}(t), t \in\left(0, T_{1}\right)$, $i=\overline{1, n_{0}}$ are the continuous functions on the time interval $\left(0, T_{1}\right)$ and belong to set $V$ :

$$
V=\left\{v(\cdot): \underline{v}_{i}(t) \leqslant v_{i}(t) \leqslant \bar{v}_{i}(t), t \in\left(0, T_{1}\right), i=\overline{1, n_{0}}\right\},
$$

where $\underline{v}_{i}(t), \bar{v}_{i}(t), t \in\left(0, T_{1}\right), i=\overline{1, n_{0}}$ are the known functions and the next conditions are satisfied:

$$
y_{i}(t)-\bar{v}_{i}(t)>0, \quad t \in\left(0, T_{1}\right), \quad i=\overline{1, n_{0}} .
$$

The set $G$ also has the following form $G=G_{1} \times G_{2}$, where $G_{1} \in \mathbb{L}_{2}\left(0, T_{1}\right), G_{2} \in \mathbb{L}_{2}\left(T_{1}, T_{2}\right)$.

A posteriori set $F_{y}$ is presented in the form:

$$
F_{y}=\left\{f(\cdot): f(\cdot) \in \bar{G}_{1} \times G_{2}\right\},
$$

where $\bar{G}_{1}=\left\{f(\cdot): \underline{v}_{i}(t) \leqslant y_{i}(t)-x_{i}(t ; f(\cdot)) \leqslant \bar{v}_{i}(t), t \in\left(0, T_{1}\right), i=\overline{1, n_{0}}\right\}$.

Let us denote $X_{y}$ :

$$
X_{y}=\left\{x\left(T_{2} ; f(\cdot)\right): x_{k}\left(T_{2} ; f(\cdot)\right) \in Q_{k}, k=\overline{1, n}\right\}
$$

where

$$
Q_{k}=\left\{x_{k}\left(T_{2} ; f(\cdot)\right): \min _{f_{1}(\cdot) \in F_{y}} x_{k}\left(T_{2} ; f_{1}(\cdot)\right) \leqslant x_{k}\left(T_{2} ; f(\cdot)\right) \leqslant \max _{f_{2}(\cdot) \in F_{y}} x_{k}\left(T_{2} ; f_{2}(\cdot)\right), f(\cdot) \in F_{y}\right\}, k=\overline{1, n} .
$$

Definition 1. The vector $\hat{x}\left(T_{2}\right)=\left(\hat{x}_{1}\left(T_{2}\right), \ldots, \hat{x}_{n}\left(T_{2}\right)\right)^{\mathrm{T}}$ is called guaranteed predictive estimation of the vector $x\left(T_{2} ; f(\cdot)\right)$ if the next condition is satisfied:

$$
\min _{x\left(T_{2} ; f(\cdot)\right) \in X_{y}} \Phi\left(x\left(T_{2} ; f(\cdot)\right)\right)=\Phi\left(\hat{x}\left(T_{2}\right)\right),
$$

here functional $\Phi\left(x\left(T_{2} ; f(\cdot)\right)\right)$ is given by:

$$
\Phi\left(x\left(T_{2} ; f(\cdot)\right)\right)=\sum_{k=1}^{n} \max _{\bar{x}\left(T_{2} ; f(\cdot)\right) \in Q_{k}}\left|x_{k}\left(T_{2} ; f(\cdot)\right)-\bar{x}\left(T_{2} ; f(\cdot)\right)\right| \beta_{k},
$$

where $\beta_{k} \geqslant 0, k=\overline{1, n}$ are the known scalar values and they fulfills equality $\sum_{k=1}^{n} \beta_{k}=1$.

Value $\sigma=\Phi\left(\hat{x}\left(T_{2}\right)\right)$ is called guaranteed predictive error of the guaranteed predictive estimation $\hat{x}\left(T_{2}\right)$.

Lemma 1. Let the conditions $x_{k}^{0}>0, k=\overline{1, n}$ for (1) are satisfied. The solutions of the system (1) take form:

$$
x_{k}(t ; f(\cdot))=\exp \left\{\varphi_{k}(t ; f(\cdot))\right\}, \quad t \in\left(0, T_{2}\right), \quad k=\overline{1, n},
$$

where vector-valued function $\varphi(t ; f(\cdot))=\left(\varphi_{1}(t ; f(\cdot)), \ldots, \varphi_{n}(t ; f(\cdot))\right)^{\mathrm{T}}, t \in\left(0, T_{2}\right)$ is the solution of the Cauchy's problem:

$$
\frac{d \varphi(t ; f(\cdot))}{d t}=A(t) \varphi(t ; f(\cdot))+B(t) f(t), \quad \varphi(0 ; f(\cdot))=\left(\ln x_{1}^{0}, \ldots, \ln x_{n}^{0}\right)^{\mathrm{T}}, \quad t \in\left(0, T_{2}\right) .
$$

Mathematical Modeling and Computing, Vol. 6, No. 1, pp. 92-100 (2019) 
Proof. The equations are satisfied:

$$
\frac{d \ln x_{k}(t ; f(\cdot))}{d t}=\frac{d x_{k}(t ; f(\cdot))}{d t} x_{k}^{-1}(t ; f(\cdot)), \quad t \in\left(0, T_{2}\right), \quad k=\overline{1, n} .
$$

Let denote $\ln x_{k}(t ; f(\cdot))=\varphi_{k}(t ; f(\cdot)), t \in\left(0, T_{2}\right), k=\overline{1, n}$ and we obtain (4). This confirms satisfaction of (3).

\section{Predictive estimation method}

Theorem 2. The components of vector of the guaranteed predictive estimation $\hat{x}\left(T_{2}\right)$ are calculated by the formulas:

$$
\hat{x}_{k}\left(T_{2}\right)=\exp \left\{\hat{\varphi}_{k}\left(T_{2}\right)\right\} \cosh \sigma_{\varphi_{k}}\left(T_{2}\right), \quad k=\overline{1, n}
$$

(and the guaranteed error of the guaranteed predictive estimation takes the form $\sigma=$ $\left.\sum_{k=1}^{n} \exp \left\{\hat{\varphi}_{k}\left(T_{2}\right)\right\} \sinh \sigma_{\varphi_{k}}\left(T_{2}\right) \beta_{k}\right)$, where the guaranteed predictive estimations $\hat{\varphi}_{k}\left(T_{2}\right), k=\overline{1, n}$ and the guaranteed errors $\sigma_{\varphi_{k}}\left(T_{2}\right), k=\overline{1, n}$ of the predictive estimation of functions $\varphi_{k}\left(T_{2} ; f(\cdot)\right), k=\overline{1, n}$ satisfy representations:

$$
\begin{aligned}
& \hat{\varphi}_{k}\left(T_{2}\right)=\frac{1}{2}\left(\varphi_{k}^{+}\left(T_{2}\right)+\varphi_{k}^{-}\left(T_{2}\right)\right), \sigma_{\varphi_{k}}\left(T_{2}\right)=\frac{1}{2}\left(\varphi_{k}^{+}\left(T_{2}\right)-\varphi_{k}^{-}\left(T_{2}\right)\right), \quad k=\overline{1, n}, \\
& \varphi_{k}^{+}\left(T_{2}\right)=\ln x_{k}^{+}\left(T_{2}\right), \quad \varphi_{k}^{-}\left(T_{2}\right)=\ln x_{k}^{-}\left(T_{2}\right), \quad k=\overline{1, n}, \\
& x_{k}^{+}\left(T_{2}\right)=\max _{f(\cdot) \in F_{y}} x_{k}\left(T_{2} ; f(\cdot)\right), \quad x_{k}^{-}\left(T_{2}\right)=\min _{f(\cdot) \in F_{y}} x_{k}\left(T_{2} ; f(\cdot)\right), \quad k=\overline{1, n} .
\end{aligned}
$$

Proof. The set $G$ is bounded, convex and closed therefore the set $F_{y}$ is bounded, convex and closed too. Thus we can find functions $\underline{f}^{k}(\cdot) \in F_{y}$ and $\bar{f}^{k}(\cdot) \in F_{y}, k=\overline{1, n}$ for which the next equalities are fulfilled:

$$
\begin{aligned}
& \max _{x_{k}\left(T_{2} ; f(\cdot)\right) \in Q_{k}} x_{k}\left(T_{2} ; f(\cdot)\right)=x_{k}\left(T_{2} ; \bar{f}^{k}(\cdot)\right)=x_{k}^{+}\left(T_{2}\right), \quad k=\overline{1, n}, \\
& \min _{x_{k}\left(T_{2} ; f(\cdot)\right) \in Q_{k}} x_{k}\left(T_{2} ; f(\cdot)\right)=x_{k}\left(T_{2} ; \underline{f}^{k}(\cdot)\right)=x_{k}^{-}\left(T_{2}\right), \quad k=\overline{1, n} .
\end{aligned}
$$

We present the expression (2) in the following form:

$$
\begin{aligned}
\max _{\bar{x}_{k}\left(T_{2} ; f(\cdot)\right) \in Q_{k}} \mid x_{k}\left(T_{2} ; f(\cdot)\right)- & \bar{x}_{k}\left(T_{2} ; f(\cdot)\right) \mid \\
& =\left\{\begin{array}{l}
x_{k}\left(T_{2} ; f(\cdot)\right)-x_{k}^{-}\left(T_{2}\right), \quad \text { at } \quad x_{k}\left(T_{2} ; f(\cdot)\right) \geqslant \frac{1}{2}\left(x_{k}^{+}\left(T_{2}\right)+x_{k}^{-}\left(T_{2}\right)\right), \\
x_{k}^{+}\left(T_{2}\right)-x_{k}\left(T_{2} ; f(\cdot)\right), \quad \text { at } \quad x_{k}\left(T_{2} ; f(\cdot)\right) \leqslant \frac{1}{2}\left(x_{k}^{+}\left(T_{2}\right)+x_{k}^{-}\left(T_{2}\right)\right) .
\end{array}\right.
\end{aligned}
$$

The last ratio can be presented as:

$$
\begin{aligned}
\max _{\bar{x}_{k}\left(T_{2} ; f(\cdot)\right) \in Q_{k}}\left|x_{k}\left(T_{2} ; f(\cdot)\right)-\bar{x}_{k}\left(T_{2} ; f(\cdot)\right)\right| \\
=\frac{1}{2}\left(x_{k}^{+}\left(T_{2}\right)-x_{k}^{-}\left(T_{2}\right)\right)+\left|x_{k}\left(T_{2} ; f(\cdot)\right)-\frac{1}{2}\left(x_{k}^{+}\left(T_{2}\right)-x_{k}^{-}\left(T_{2}\right)\right)\right|, \quad k=\overline{1, n} .
\end{aligned}
$$

On the basis of $(2)$ and (6) we obtain equation for the functional $\Phi\left(x\left(T_{2} ; f(\cdot)\right)\right)$ :

$$
\Phi\left(x\left(T_{2} ; f(\cdot)\right)\right)=\sum_{k=1}^{n}\left[\frac{1}{2}\left(x_{k}^{+}\left(T_{2}\right)-x_{k}^{-}\left(T_{2}\right)\right)+\left|x_{k}\left(T_{2} ; f(\cdot)\right)-\frac{1}{2}\left(x_{k}^{+}\left(T_{2}\right)-x_{k}^{-}\left(T_{2}\right)\right)\right|\right] \beta_{k} .
$$

Mathematical Modeling and Computing, Vol. 6, No. 1, pp. 92-100 (2019) 
We can find the formulas to finding component of vector of the guaranteed predictive estimation $\hat{x}\left(T_{2}\right)$ and the guaranteed error from the last expression:

$$
\begin{aligned}
\hat{x}_{k}\left(T_{2}\right) & =\frac{1}{2}\left(x_{k}^{+}\left(T_{2}\right)+x_{k}^{-}\left(T_{2}\right)\right), \quad k=\overline{1, n}, \\
\sigma & =\frac{1}{2} \sum_{k=1}^{n}\left(x_{k}^{+}\left(T_{2}\right)-x_{k}^{-}\left(T_{2}\right)\right) \beta_{k} .
\end{aligned}
$$

On the basis of (7), (8) and (4) we get:

$$
\begin{aligned}
\hat{x}_{k}\left(T_{2}\right) & =\frac{1}{2}\left(e^{\varphi_{k}^{+}\left(T_{2}\right)}+e^{\varphi_{k}^{-}\left(T_{2}\right)}\right), \quad k=\overline{1, n}, \\
\sigma & =\frac{1}{2} \sum_{k=1}^{n}\left(e^{\varphi_{k}^{+}\left(T_{2}\right)}+e^{\varphi_{k}^{-}\left(T_{2}\right)}\right) \beta_{k} .
\end{aligned}
$$

Since

$$
\varphi_{k}^{+}\left(T_{2}\right)=\hat{\varphi}_{k}\left(T_{2}\right)+\sigma_{\varphi_{k}}\left(T_{2}\right), \varphi_{k}^{-}\left(T_{2}\right)=\hat{\varphi}_{k}\left(T_{2}\right)-\sigma_{\varphi_{k}}\left(T_{2}\right), \quad k=\overline{1, n}
$$

thus we get

$$
\begin{aligned}
\sigma & =\frac{1}{2} \sum_{k=1}^{n}\left(e^{\hat{\varphi}_{k}\left(T_{2}\right)+\sigma_{\varphi_{k}}\left(T_{2}\right)}-e^{\hat{\varphi}_{k}\left(T_{2}\right)-\sigma_{\varphi_{k}}\left(T_{2}\right)}\right) \beta_{k} \\
& =\sum_{k=1}^{n} e^{\hat{\varphi}_{k}\left(T_{2}\right)} \frac{1}{2}\left(e^{\sigma_{\varphi_{k}}\left(T_{2}\right)}-e^{-\sigma_{\varphi_{k}}\left(T_{2}\right)}\right) \beta_{k}=\sum_{k=1}^{n} \exp \left\{\hat{\varphi}_{k}\left(T_{2}\right)\right\} \sinh \sigma_{\varphi_{k}}\left(T_{2}\right) \beta_{k}, \\
\hat{x}_{k}\left(T_{2}\right) & =\frac{1}{2}\left(e^{\hat{\varphi}_{k}\left(T_{2}\right)+\sigma_{\varphi_{k}}\left(T_{2}\right)}+e^{\hat{\varphi}_{k}\left(T_{2}\right)-\sigma_{\varphi_{k}}\left(T_{2}\right)}\right) \\
& =e^{\hat{\varphi}_{k}\left(T_{2}\right)} \frac{1}{2}\left(e^{\sigma_{\varphi_{k}}\left(T_{2}\right)}+e^{-\sigma_{\varphi_{k}}\left(T_{2}\right)}\right)=\exp \left\{\hat{\varphi}_{k}\left(T_{2}\right)\right\} \cosh \sigma_{\varphi_{k}}\left(T_{2}\right), \quad k=\overline{1, n} .
\end{aligned}
$$

The theorem has been proven.

Theorem 3. The set $F_{y}$ also has the form:

$$
\begin{gathered}
F_{y}=\left\{f(\cdot): f(\cdot) \in \overline{\bar{G}}_{1} \times G_{2}\right\}, \\
\overline{\bar{G}}_{1}=\left\{f(\cdot):\left|\varphi_{i}(t ; f(\cdot))-\bar{\varphi}_{i}(t)\right| \leqslant \delta_{i}(t), t \in\left(0, T_{1}\right), i=\overline{1, n_{0}}\right\},
\end{gathered}
$$

where $\varphi_{i}(t), i=\overline{1, n_{0}}, t \in\left(0, T_{1}\right)$ are the solution of the Cauchy's problem (4) and

$$
\begin{array}{ll}
\bar{\varphi}_{i}(t)=\frac{1}{2}\left(y_{i}^{+}(t)+y_{i}^{-}(t)\right), \quad \delta_{i}(t)=\frac{1}{2}\left(y_{i}^{+}(t)-y_{i}^{-}(t)\right), \quad t \in\left(0, T_{1}\right), \quad i=\overline{1, n_{0}} \\
y_{i}^{-}(t)=\ln \left(y_{i}(t)-\bar{v}_{i}(t)\right), \quad y_{i}^{+}(t)=\ln \left(y_{i}(t)-\underline{v}_{i}(t)\right), \quad t \in\left(0, T_{1}\right), \quad i=\overline{1, n_{0}} .
\end{array}
$$

Proof. Since the inequalities satisfy:

$$
\begin{aligned}
-\bar{v}_{i}(t) \leqslant x_{i}(t ; f(\cdot))-y_{i}(t) \leqslant & -\underline{v}_{i}(t), \quad t \in\left(0, T_{1}\right), \quad i=\overline{1, n_{0}} \\
& \Leftrightarrow y_{i}(t)-\bar{v}_{i}(t) \leqslant x_{i}(t ; f(\cdot)) \leqslant y_{i}(t)-\underline{v}_{i}(t), \quad t \in\left(0, T_{1}\right), \quad i=\overline{1, n_{0}},
\end{aligned}
$$

we have expression:

$$
\ln \left(y_{i}(t)-\bar{v}_{i}(t)\right) \leqslant \varphi_{i}(t ; f(\cdot)) \leqslant \ln \left(y_{i}(t)-\underline{v}_{i}(t)\right), \quad t \in\left(0, T_{1}\right), \quad i=\overline{1, n_{0}},
$$

Mathematical Modeling and Computing, Vol. 6, No. 1, pp. 92-100 (2019) 
i.e.

$$
y_{i}^{-}(t) \leqslant \varphi_{i}(t ; f(\cdot)) \leqslant y_{i}^{+}(t), \quad t \in\left(0, T_{1}\right), \quad i=\overline{1, n_{0}} .
$$

On the basis (9) the last inequalities take the form:

$$
\left\{\begin{aligned}
\varphi_{i}(t ; f(\cdot)) \leqslant \bar{\varphi}_{i}(t)+\delta_{i}(t), \quad t \in\left(0, T_{1}\right), & i=\overline{1, n_{0}}, \\
\varphi_{i}(t ; f(\cdot)) \geqslant \bar{\varphi}_{i}(t)-\delta_{i}(t), \quad & \Leftrightarrow\left|\varphi_{i}(t ; f(\cdot))-\bar{\varphi}_{i}(t)\right| \leqslant \delta_{i}(t), \quad t \in\left(0, T_{1}\right), \quad i=\overline{1, n_{0}} .
\end{aligned}\right.
$$

The theorem has been proven.

To define the matrix-valued function $\Phi(t, s), t \in\left(s, T_{2}\right), s \in\left(0, T_{2}\right)$ in the form of the solution of the Cauchy's problem:

$$
\frac{d \Phi(t, s)}{d t}=A(t) \Phi(t, s), \quad \Phi(s, s)=\mathrm{E}, \quad t \in\left(s, T_{2}\right), \quad s \in\left(0, T_{2}\right),
$$

where $\mathrm{E} \in \mathbb{R}^{n \times n}$ is the identity matrix.

Let $\left(\widehat{\left(T_{1}\right),} g^{k}\right), k=\overline{1, n}$ are the guaranteed estimation of values $\left(\varphi\left(T_{1} ; f(\cdot)\right) ; g^{k}\right), k=\overline{1, n}$, where $g^{k}=\Phi^{\mathrm{T}}\left(T_{2}, T_{1}\right) e^{k}, k=\overline{1, n}$.

Lemma 4. The next equalities are fulfilled for the values $\left(\widehat{\varphi\left(T_{1}\right), g^{k}}\right), k=\overline{1, n}$ :

$$
\hat{x}_{k}\left(T_{2}\right)=\exp \left\{\left(\widehat{\varphi\left(T_{1}\right), g^{k}}\right)+\hat{\psi}_{k}\left(T_{2}\right)\right\} \cosh \sigma_{\varphi_{k}}\left(T_{2}\right), \quad k=\overline{1, n},
$$

where

$$
\hat{\psi}_{k}\left(T_{2}\right)=\frac{1}{2}\left[\max _{f(\cdot) \in G_{2}}\left(\psi_{k}\left(T_{2} ; f(\cdot)\right), e^{k}\right)+\min _{f(\cdot) \in G_{2}}\left(\psi_{k}\left(T_{2} ; f(\cdot)\right), e^{k}\right)\right], \quad k=\overline{1, n}
$$

and $\psi(t ; f(\cdot))=\left(\psi_{1}(t ; f(\cdot)), \ldots, \psi_{n}(t ; f(\cdot))\right)^{\mathrm{T}}, t \in\left(T_{1}, T_{2}\right)$ is found as the solution of the Cauchy's problem:

$$
\frac{d \psi(t ; f(\cdot))}{d t}=A(t) \psi(t ; f(\cdot))+B(t) f(t), \quad t \in\left(T_{1}, T_{2}\right), \quad \psi\left(T_{1}, f(\cdot)\right)=0 .
$$

Proof. The next expression is fulfilled at some point in time $t \in\left(T_{1}, T_{2}\right)$ :

$$
\varphi(t ; f(\cdot))=\Phi\left(t, T_{1}\right) \varphi\left(T_{1} ; f(\cdot)\right)+\psi(t ; f(\cdot)), \quad t \in\left(T_{1}, T_{2}\right) .
$$

Thus we get:

$$
\varphi_{k}\left(T_{2} ; f(\cdot)\right)=\left(\varphi\left(T_{1} ; f(\cdot)\right), g^{k}\right)+\psi_{k}\left(T_{2} ; f(\cdot)\right), \quad k=\overline{1, n} .
$$

The next representations are satisfied for components of vector of the guaranteed estimation $\hat{\varphi}\left(T_{2}\right)=$ $\left(\hat{\varphi}_{1}\left(T_{2}\right), \ldots, \hat{\varphi}_{n}\left(T_{2}\right)\right)^{\mathrm{T}}$ :

$$
\hat{\varphi}_{k}\left(T_{2}\right)=\left(\widehat{\varphi\left(T_{1}\right), g^{k}}\right)+\hat{\psi}_{k}\left(T_{2}\right), \quad k=\overline{1, n} .
$$

Applying (11) to (5) and we obtaine expression (10). The lemma has been proven.

Corollary 1. The set $G$ is bounded, convex, closed and centrally symmetric with respect to certain function $\tilde{f}(t), t \in\left(0, T_{2}\right)$. Thus we obtain:

$$
\hat{\psi}_{k}\left(T_{2}\right)=\left(\hat{\psi}\left(T_{2}\right), e^{k}\right), \quad k=\overline{1, n},
$$

where vector-valued function $\hat{\psi}(t), t \in\left(T_{1}, T_{2}\right)$ is the solution of the Cauchy's problem:

$$
\frac{d \hat{\psi}(t)}{d t}=A(t) \hat{\psi}(t)+B(t) \tilde{f}(t), \quad t \in\left(T_{1}, T_{2}\right), \quad \hat{\psi}\left(T_{1}\right)=0 .
$$

Mathematical Modeling and Computing, Vol. 6, No. 1, pp. 92-100 (2019) 


\section{Algorithms for finding approximate predictive estimation}

Now let us investigate the problem of finding the approximate predictive estimation of the values $x_{k}\left(T_{2} ; f(\cdot)\right), k=\overline{1, n}$ under uncertainty.

Denote $F_{1 y}$ as the approximation of the set $F_{y}$ :

$$
F_{1 y}=\left\{f(\cdot): I_{y}(f(\cdot)) \leqslant \gamma^{2}\right\} \times G_{2},
$$

where

$$
I_{y}(f(\cdot))=\int_{0}^{T_{2}} q_{1}^{2}(t)|f(t)-\tilde{f}(t)|^{2} d t+\sum_{i=1}^{n_{0}} \int_{0}^{T_{1}} \delta_{i}^{-2}(t)\left|\left(\varphi(t ; f(\cdot)), e^{i}\right)-\bar{\varphi}(t)\right|^{2} d t
$$

$q_{1}^{2}(t), t \in\left(0, T_{2}\right)$ is the non-negative continuous function on the time interval $\left(0, T_{2}\right), \tilde{f}(t), t \in\left(0, T_{2}\right)$ is the known vector-value function in $\mathbb{L}_{2}\left(0, T_{2}\right)$ (moreover the functions $q_{1}^{2}(t), \tilde{f}(t), t \in\left(0, T_{2}\right)$ and constant $\gamma^{2}$ are chosen in such a way that the condition $F_{y} \subset F_{1 y}$ fulfills); the functions $\delta_{i}^{-2}(t)$ and $\bar{\varphi}_{i}(t), t \in\left(0, T_{1}\right), i=\overline{1, n_{0}}$ are calculated by $(9)$.

Definition 2. The set $F_{1 y}$ is called approximate a priori set of $F_{y}$.

Now let us find the guaranteed predictive estimations of values $\varphi_{k}\left(T_{2} ; f(\cdot)\right)=\left(\varphi\left(T_{2} ; f(\cdot)\right), e^{k}\right)$, $k=\overline{1, n}$ for the approximate a priori set $F_{1 y}$.

On the basis [9] these estimations take the form:

$$
\hat{\varphi}_{k}\left(T_{2}\right)=\left(\hat{\varphi}\left(T_{2}\right), e^{k}\right), \quad k=\overline{1, n},
$$

and the guaranteed errors for estimation fulfill the next inequalities:

$$
\sigma_{\varphi_{k}}\left(T_{2}\right) \leqslant\left(e^{k}, P\left(T_{2}\right) e^{k}\right), \quad k=\overline{1, n} .
$$

Here

$$
\hat{\varphi}_{k}(t)=\left\{\begin{array}{l}
\hat{\varphi}_{k 1}(t), \quad t \in\left(0, T_{1}\right), \\
\hat{\varphi}_{k 2}(t), \quad t \in\left(T_{1}, T_{2}\right), \quad k=\overline{1, n},
\end{array}\right.
$$

are found as the solution of the Cauchy's problem:

$$
\left\{\begin{array}{l}
\frac{d \hat{\varphi}_{k 1}(t)}{d t}=\sum_{j=1}^{n}\left(A(t) e^{k}, e^{j}\right) \hat{\varphi}_{k 1}(t)+\left(B(t) \tilde{f}(t), e^{k}\right)+\delta_{k}^{2}(t)\left(\bar{\varphi}_{k}(t)-\hat{\varphi}_{k 1}(t)\right), \quad t \in\left(0, T_{1}\right) \\
\hat{\varphi}_{k 1}(0)=\ln x_{0}^{k}, \quad k=\overline{1, n} \\
\frac{d \hat{\varphi}_{k 2}(t)}{d t}=\sum_{j=1}^{n}\left(A(t) e^{k}, e^{j}\right) \hat{\varphi}_{k 2}(t)+\left(B(t) \tilde{f}(t), e^{k}\right), \quad t \in\left(T_{1}, T_{2}\right), \\
\hat{\varphi}_{k 2}\left(T_{1}\right)=\hat{\varphi}_{k 1}\left(T_{1}\right), \quad k=\overline{1, n}
\end{array}\right.
$$

matrix-value function $P(t), t \in\left(0, T_{2}\right)$ is calculated by formulas:

$$
\begin{gathered}
P(t)=\left\{\begin{array}{l}
P_{1}(t), t \in\left(0, T_{1}\right), \\
P_{2}(t), t \in\left(T_{1}, T_{2}\right),
\end{array}\right. \\
\left\{\begin{array}{l}
\frac{d P_{1}(t)}{d t}=A(t) P_{1}(t)+P_{1}(t) A^{\mathrm{T}}(t)-P_{1}(t) H^{\mathrm{T}} Q(t) H P_{1}(t)+q_{1}^{2}(t) \mathrm{E}, \quad t \in\left(0, T_{1}\right), \quad P_{1}(0)=0, \\
\frac{d P_{2}(t)}{d t}=A(t) P_{2}(t)+P_{2}(t) A^{\mathrm{T}}(t), \quad t \in\left(T_{1}, T_{2}\right), \quad P_{2}\left(T_{1}\right)=P_{1}\left(T_{1}\right),
\end{array}\right.
\end{gathered}
$$




$$
\begin{gathered}
H=\left\{h_{i j}\right\}=\left(\begin{array}{cccccc}
1 & 0 & \ldots & 0 & \ldots & 0 \\
0 & 1 & \ldots & 0 & \ldots & 0 \\
\ldots & \ldots & \ldots & \ldots & \ldots & \ldots \\
0 & 0 & \ldots & 1 & \ldots & 0
\end{array}\right), \quad h_{i j}=\delta_{i j}, \quad i=\overline{1, n_{0}}, \quad j=\overline{1, n}, \\
Q(t)=\operatorname{diag}\left(\delta_{1}^{2}(t), \ldots, \delta_{n_{0}}^{2}(t)\right), \quad t \in\left(0, T_{1}\right),
\end{gathered}
$$

and $\delta_{i j}, i=\overline{1, n_{0}}, j=\overline{1, n}$ is Kronecker delta.

On the basis (12) and (13) components of the guaranteed predictive estimation $\hat{x}\left(T_{2}\right)$ is calculated by formulas (5).

\section{Results of numerical experiment}

The results of building guaranteed predictive estimation for the model of the information spreading of one type messages process in society are given as an example. The problem of constructing and model analysis of the information spreading process in the form of the differential equation system was considered in works $[2,7,10-14]$.

Let us consider a certain social community. Suppose, a community is influenced by one sources of information at some point in time $t \in\left(0, T_{2}\right)$. The numbers of people who have accepted the information messages the information flow depends on external influence and interpersonal communication. This process is modeled as one ordinary differential non-linear equation.

Let us denote $a(t), t \in\left(0, T_{2}\right)$ the known intensity of communication at some point in time $t \in$ $\left(0, T_{2}\right) ; f(t), t \in\left(0, T_{2}\right), f(\cdot) \in \mathbb{L}_{2}\left(0, T_{2}\right)$ the unknown external influence at some point in time $t \in\left(0, T_{2}\right) ; x(t ; f(\cdot)), t \in\left(0, T_{2}\right)$ the numbers of people, who have accepted the information messages from information flow at some point of time $t \in\left(0, T_{2}\right)$. And the $x(0 ; f(\cdot))$ satisfy the inequality $x(0 ; f(\cdot))=x^{0}>0$. Time variable of value $x(t ; f(\cdot)), t \in\left(0, T_{2}\right)$ we describe by Cauchy's problem:

$$
\frac{d x(t ; f(\cdot))}{d t}=(a(t) \ln x(t ; f(\cdot))+f(t)) x(t ; f(\cdot)), \quad t \in\left(0, T_{2}\right), \quad x(0 ; f(\cdot))=x^{0} .
$$

Suppose that $y(t), t \in\left(0, T_{1}\right)$ are the known observations of the function $x(t ; f(\cdot)), t \in\left(0, T_{1}\right)$ with the certain $f(t), t \in\left(0, T_{1}\right)$ :

$$
y(t)=x(t ; f(\cdot))+v(t), \quad t \in\left(0, T_{1}\right),
$$

where $v(t), t \in\left(0, T_{1}\right)$ are the unknown observed error.
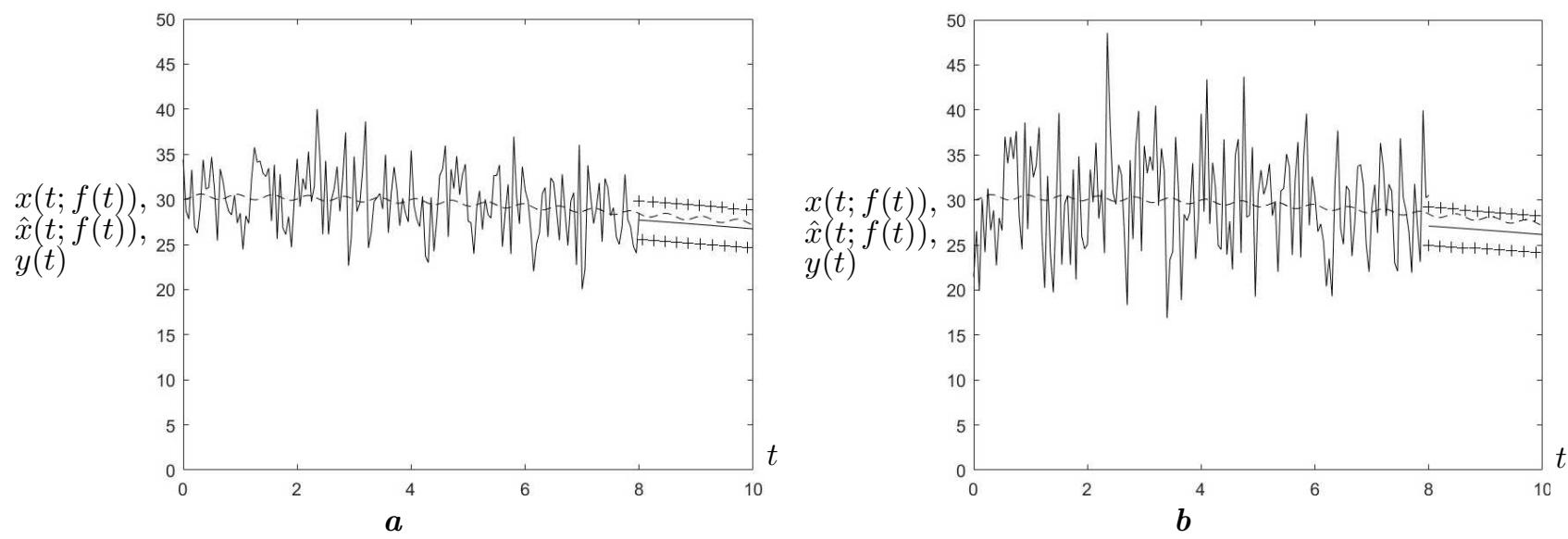

Fig. 1. Guaranteed predictive estimation for the model (14), where dotted line is for $x(t ; f(\cdot)), t \in(0 ; 10)$, full line is for observation $y(t), t \in(0 ; 8)$ and guaranteed predictive $\hat{x}(t), t \in(8 ; 10)$, symbols ' + ' is for margin of error guaranteed predictive estimation $\hat{x}(t), t \in(8 ; 10)$. 
The results of building guaranteed predictive estimation for the model (14) where parameters satisfy: $T_{1}=8, T_{2}=10, x(0 ; f(\cdot))=30, a(t)=-0.0006 t, q_{1}^{2}(t)=1, \tilde{f}(t)=0, t \in(0 ; 10)$ and observation (15) (random $v(t), t \in(0 ; 8)$ to be normally distributed $N(0 ; 16)$ ) are presented in Fig. $1 a$.

The results of building guaranteed predictive estimation for the model (14) where parameters satisfy: $T_{1}=8, T_{2}=10, x(0 ; f(\cdot))=30, a(t)=-0.0006 t, q_{1}^{2}(t)=1, \tilde{f}(t)=0, t \in(0 ; 10)$ and observation (15) (random $v(t), t \in(0 ; 8)$ to be normally distributed $N(0 ; 36)$ ), are presented in Fig. $1 b$.

Based on the analysis of the graphs, it can be concluded, that the algorithm gives the sufficient guaranteed predictive estimate in case of significant observed errors.

\section{Conclusions}

We have developed a novel approach to algorithm constructing for guaranteed predictive estimation for models with Gompertzian dynamics in the case of continuous observation. Moreover, we have investigated the case of supporters of both information flows with known system parameters for given equations. In addition, we have considered the case of supporters of both information flows with known system parameters. The numerical experiments of building guaranteed predictive estimation for the model of the information spreading of one type messages process in society are given as an example. The analysis of these results has demonstrated the practical meaning of the obtained approach. The obtained results can be useful for special case of information spreading process models.

[1] Kalas J., Novotny J., Michalek J., Nakonechnyi O. G. Mathematical model for cancer prevalence and cancer mortality. Taurida Journal of Computer Science Theory and Mathematics. 2, 44-54 (2013).

[2] Nakonechnyi O. G., Zinko P. M. Confrontation problems with the dynamics Gompertzian systems. Journal of Computational and Applied Mathematics. 3 (120), 50-60 (2015), (in Ukrainian).

[3] Nakonechnyi O. G. Parameters estimation under uncertainty. Scientific notes of National University of Kyiv, Faculty of Cybernetics. VII, 102-111 (2004), (in Ukrainian).

[4] Nakonechnyi O. G. Problem of guaranteed estimation of parameters in dynamics. Abstracts XVII International Conference "Problem of decision making under uncertainties". Shidnycya, Ukraine. May 23-27. P. 141 (2011), (in Ukrainian).

[5] Nakonechnyi O. G., Zinko P. M., Shevchuk I. M. Predictive estimation of mathematical models of information spreading process under uncertainty. System Research and Information Technologies. 4, 54-65 (2017), (in Ukrainian).

[6] Nakonechnyi O. G., Shevchuk I. M., Chicrii V.K. Estimation of non-stationary parameters of differential equations under uncertainty. Cybernetics and system analysis. 4, 109-121 (2018), (in Ukrainian).

[7] Nakonechnyi O. G., Zinko P. M., Shevchuk I. M. Guaranteed estimation of non-stationary parameters of difference equations under uncertainty. Journal of Automation and Information Sciences. 6, 41-54 (2018), (in Russian).

[8] Nakonechnyi O. G. Problem of guaranteed estimation of parameters in dynamics. Abstracts XXXIII International Conference "Problem of decision making under uncertainties". Hurgada, Egypt. Jauare 24 February 1. P. 64-66 (2019).

[9] Bublik B. N., Danilov V. Y., Nakonechnyi O. G. Some observation and control problems in linear systems. Kyiv, UMK VO (1988), (in Russian).

[10] Mikhailov A. P., Marevtseva N. A. Models of Information Warfare. Mathematical Models and Computer Simulations. 4 (3), 251-259 (2012).

[11] Mishra B. K., Prajapati A. Modelling and simulation: cyber war. Procedia Technology. 10, 987-997 (2013).

[12] Kereselidze N. G. An optimal control problem in mathematical and computer models of the information warfare. Differential and Difference Equations with Applications: ICDDEA, Amadora, Portugal, May 2015, Selected Contributions. Springer Proceedings in Mathematics and Statistics, 164. Springer International Publishing Switzerland. P. 303-311 (2015). 
[13] Nakonechnyi O.G., Shevchuk I. M. Mathematical model of information spreading process with nonstationary parameters. Bulletin of Taras Shevchenko National University of Kiev. Series Physics and Mathematics. 3, 98-105 (2016), (in Ukrainian).

[14] Ivokhin E. V., Adzhubey L. T., Gavrylenko E. V. Guaranteed estimation of non-stationary parameters of difference equations under uncertainty. Journal of Automation and Information Sciences. 1, 5-12 (2019), (in Russian).

\title{
Гарантовані прогнозні оцінки розв“язків систем диференціальних рівнянь із динамікою Гомперца
}

\author{
Наконечний О., Зінько П., Шевчук Ю. \\ Київсъкий начіональний університет імені Тараса Шевченка, \\ вул. Володимирсъка, 64/13, Київ, 01601, Украӥна
}

\begin{abstract}
У роботі досліджено математичну модель у формі системи нелінійних диференціальних рівнянь із динамікою Гомперца, яка може бути застосована для моделювання процесів, що швидко зростають за часом. Сформульовано та розв'язано задачу знаходження гарантованих прогнозних оцінок для систем диференціальних рівнянь 3 динамікою Гомперца для випадку неперервних спостережень. Як приклади подано результати визначення гарантованих прогнозних оцінок динаміки математичної моделі поширення одного виду інформації в соціумі.
\end{abstract}

Ключові слова: системи нелінійних диференціальних рівнянь, динаміка Гомпериа, прогнозні гарантовані оцінки, невизначеність.

2000 MSC: 34-02, 90-02

Удк: $517.9,519.87$ 